\title{
STAKEHOLDER PERSPECTIVES ON BREEDING STRATEGY AND CHOICE OF BREEDS FOR LIVESTOCK DEVELOPMENT IN BANGLADESH*
}

\author{
M. A. Jabbar ${ }^{1}$, S. S. Husain', S. M. F. Islam³ , M. R. Amin' ${ }^{4}$ M. A. M. Y. Khandaker ${ }^{4}$, \\ A. K. F. H Bhuiyan ${ }^{4}$, S. Z. Ali $^{4}$ and O. Faruque ${ }^{4}$
}

\begin{abstract}
In Bangladesh, a science based systematically organized pragmatic breeding policy has never been formulated and adopted. In breeding research and development projects, perspectives of stakeholders like researchers, extension agents and farmers on criteria for selection of breeds for adaptation in the country have not been adequately considered. In this paper, opinions of a sample of 128 university teachers, researchers and extension experts in the field of livestock and 196 farmers with at least one milking cow on criteria for selection of breeds and their relative weights and a number of other breed development issues are presented. The results show that there are significant differences among experts about the breeding objectives and strategies to be followed, on relative weights to be given on various traits for evaluation and selection of breeds and allocation of research resources on different species for breed development. Moreover, there are significant differences between experts and farmers about relative weights to be given for breed evaluation and selection, and on the extent of suitability of different available breeds for local adaptation. These results indicate that breeding research and development needs to be based on more such studies to facilitate serious debate and arrive at a consensus for adoption of long-term breeding policy.
\end{abstract}

Key words: Stakeholder, Breeding strategy, Livestock, Breed

\footnotetext{
*This is a revised version of a paper initially presented at the workshop on "Demand-led opportunities for transformation of the livestock sector : role of contract farming and breeding” organized jointly by Bangladesh Agricultural University (BAU), Mymensingh, Bangabandhu Shaikh Mujibur Rahman Agricultural University, Gazipur, and International Livestock Research Institute, Nairobi, Kenya, held at BAU, Mymensingh, on 24 May 2009, and an extended version presented at the International Dairy Conference, held at BAU, Mymensingh on 35 April 2010. Comments received at both the conferences were useful. The authors alone remain responsible for the content of the paper. The authors are:

${ }^{1}$ Ex-Senior Agricultural Economist and Team Leader, International Livestock Research Institute, Nairobi, Kenya

${ }^{2}$ Vice-Chancellor, Patuakhali University of Science and Technology, Dumki, Patuakhali. Previously Dean, Faculty of Animal Husbandry, BAU, Mymensingh.

${ }^{3}$ Professor and Head, Department of Agricultural Economics, Bangabandhu Shaikh Mujibur Rahman Agricultural University, Gazipur

${ }^{4}$ Professor, Department of Animal Breeding and Genetics, BAU, Mymensingh
}

(Received: April 22, 2010) 
Bang. J. Anim. Sci. 2010, 39(1\&2)

\section{Introduction}

\section{Background and objectives}

The Ministry of Fisheries and Livestock (MOFL) formulated a new 'National Livestock Development Policy' in 2007, which was provisionally adopted by the then Care Taker Government in 2008 (MOFL, 2007). Although the document has not been fully officially adopted, it is being used as an operational policy document. The document has a section devoted to breeding policy and breed development. In any discussion on breeding policy aimed at long-term development of breed (s) for a given context, three aspects are normally considered: choice of breeds for development, strategy for multiplication and dissemination of the chosen breeding material, and regulations for protection of property rights, trade and quality control. The section in the above document also touched on these three aspects though not in a systematic manner and not very rigorously. Specific action plans have been proposed in the policy document to address each component and reportedly these have been done on the basis of discussions and recommendations of experts in various forums. However, not all of the proposed actions and their justification appear to be clear and appropriate for the given conditions of Bangladesh.

The policy document recognized that "lack of a breeding policy, use of inappropriate breeds, weak infrastructure (human capacity, national service delivery, breeding farms), limited technical knowhow has constrained the development of improved breeds” (MOFL, 2007). Breeding research and development work has been going on in the country in the absence of any properly defined breeding policy. Artificial Insemination (AI) service providers are currently producing, importing and distributing semen of various breeds without clarification on why these options have been chosen and how such uncoordinated AI service provision will contribute to the sustained development of the national herd.

Although it may not be possible to formulate an ideal breeding policy immediately because of lack of infrastructure and institutions to implement it, at least there should be some consensus on which breeds should be promoted and why, what kind of breeding strategy should be followed in the country, what are the pros and cons of different breeding strategies, so that service providers (government, private or NGOs) may provide services with some knowledge of the consequences of any breeding service for long-term stable breed development in the country. The MOFL apparently formulated the policy on the basis of recommendations of an advisory committee, which had undertaken some consultations with experts. However, no details on the deliberations of those consultations and the basis of the choices made are available. It is assumed that there is room for more constructive debate on some of the issues to reconsider some of the decisions on the basis of more objective information. In order to facilitate such a debate or discussion, a questionnaire survey was conducted among 130 teaching, research and development experts, who constitute one set of stakeholders in the livestock sector, on their perceptions and opinions about long and shortterm strategy with respect to breeds and breed development and about criteria for choice of breeds and suitability of different breeds for development/adaptation. Moreover, a survey 
was conducted among a purposive sample of about 200 dairy farmers from several districts where commercial dairy is important to assess their perceptions and preferences on breeds and breed performance. Farmers are the key stakeholders for livestock development and there is hardly any evidence that in the past, perspectives and experiences of farmers and users of improved and crossbreeds have been taken into account in choosing breeding material for dissemination through AI and other programs such as bull stations.

In this paper, we first briefly discuss breed improvement efforts made in the past, then present the methodology and results of the surveys. Conclusions are presented at the end.

\section{Historical perspectives on breed improvement efforts}

The local non-descript cattle population in Bangladesh has evolved by adapting to its climatic conditions, available feed resources and disease incidence. Producers have continuously improved them through careful selection and grading. Formal scientific intervention in breed development is a more recent phenomenon. Efforts to improve Indian local zebu cattle through crossbreeding and grading were started by the then British Government in the middle of the nineteenth century by crossing with European breeds. In Bengal, initial effort for genetic improvement of cattle was made through importing better quality Indian breeds e.g. Haryana, Tharparkar, Red Sindhi, Sahiwal from the western part of India to the areas currently comprising Pabna and Sirajganj districts and adjoining areas. The crossbreeding activity using exotic European blood was introduced in Bengal much later.

However, the British efforts in India to improve cattle quality through crossbreeding with their exotic breeds met with little success. About forty years after the crossbreeding program was launched, Robert Wallace, a professor of agriculture at the University of Edinburgh made the following observations and recommendations after an extensive visit to India including Bengal: (a) various European breeds have been introduced in all varieties of Indian climatic conditions in pure form or cross with native cattle but they performed poorly as they could not adapt well to local climatic conditions and other stresses; and (b) local breeds could only be improved by selection of good specimens from among themselves, as no imported cattle could possess the qualities of endurance and long suffering attained in the local breed by generation of semi-starvation (Wallace, 1888).

Wallace's observations and recommendations were based on the approaches and experiences of the developed countries in terms of breed development. The advanced countries gradually scaled up their locally developed technologies, which emerged through long periods of farmer practice, experimentation and adaptation to local environments. A typical technology maturity path for crop and animal genetic research and development followed in the advanced countries is illustrated in Fig. 1. 
Bang. J. Anim. Sci. 2010, 39(1\&2)

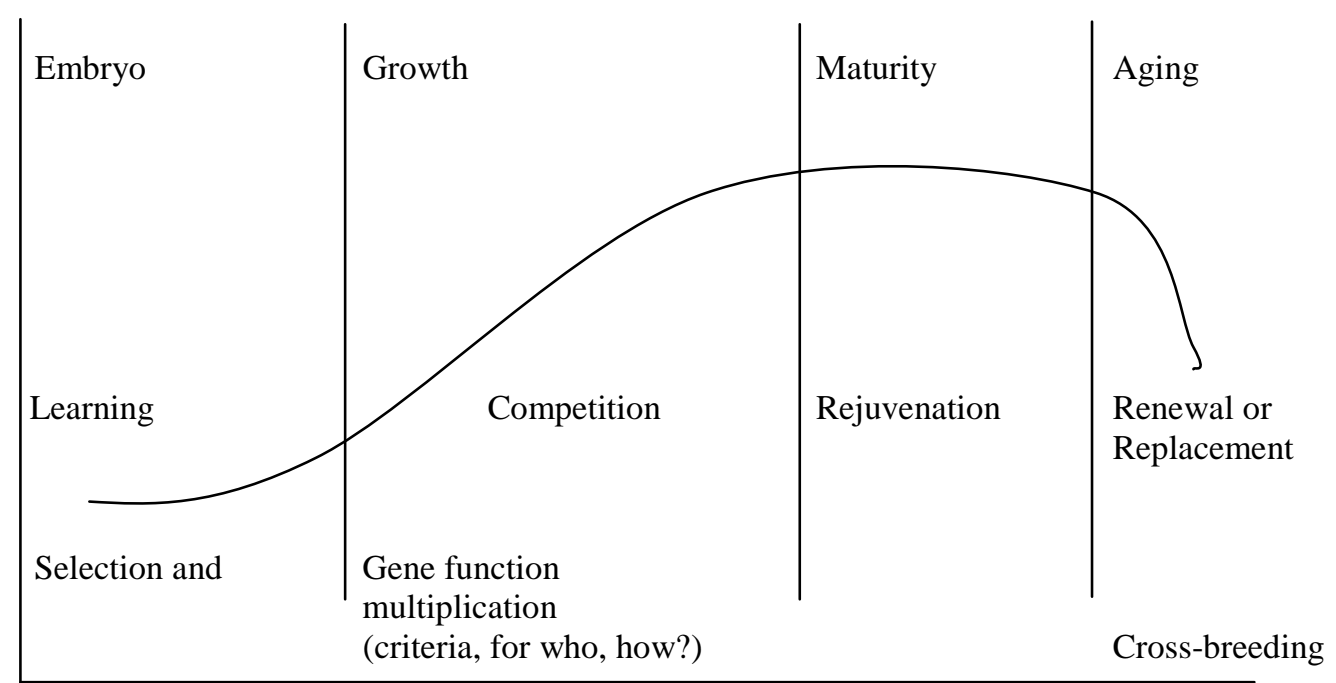

Time

Fig. 1. A typical technology maturity path and related research focus

Source : Adapted by Jabbar (2004) from Shaun Coffey, 'Objective subjectivity- it takes more than just numbers to select and evaluate research activities'. Seminar presented at ILRI, Addis Ababa, Ethiopia, 6 April, 2004.

The learning started with characterization and understanding of the inherent potential, e.g. productivity, disease resistance or other traits of the available varieties or breeds so that choices could be made for further development. Then choices were made for multiplication and dissemination. Often dissemination strategies failed if adequate attention was not given on who (resource poor or rich) the target users were, where (various production environments and systems) the varieties or breeds would fit, their resource requirements for acquisition and use etc. Where such considerations were properly given, high rate of adoption and use occurred. Newly developed breeds and varieties lost vigor over time, so needed to be rejuvenated continuously to maintain productivity, but a time came when they had to be replaced or renewed completely with better research outputs to take advantage of better productivity and cost effectiveness. Implementation of such a strategy required a portfolio of basic, strategic to adaptive research with a balance between different stages of the maturity path (Jabbar, 2004).

In the developing countries, rather than scaling up local technologies, research has often been focused on adapting or scaling down advanced technologies to local situations. Basic and strategic research has been given little emphasis even where available resources permitted; countries like India, Brazil, Korea and China have been exceptions. Adaptive research has some merits, for example, in generating quick returns where appropriate technologies can be identified, adapted and multiplied rapidly, and save resources from repeating research that has been done elsewhere. However, long-term sustainable development may not be guaranteed based only on adaptive research. 
During the green revolution era, crop researchers in some developing countries tried to follow some aspects of these principles to some extent. In the past, conventional breeding techniques were used for selection and multiplication of crop varieties. Now molecular techniques and marker assisted selection are being used. In the past user perspectives were rarely considered in selection and multiplication, so poor people's needs remained ignored. Participatory plant breeding and other means of soliciting user perspectives based on indigenous knowledge are increasingly used in variety selection, creating scope to consider poor people's needs. The combination of biotechnology and participatory approaches has great potential to make research more relevant and useful for the poor (Conway, 1999). But such systematic approach to breed development has been rarely followed in livestock research in the developing countries. Consequently, technology options for livestock development remain very limited; the choices available for supporting poor livestock keepers are even more limited (Jabbar et al., 1999).

The history of crossbreeding for improvement of cattle in many developing countries including Bangladesh and India is a good example of this deficient approach. The developed countries improved their local breeds through selection and grading and at a later stage crossing among best performing breeds or breed lines. Similarly, the best performing Indian breeds e.g. Haryana, Tharparker, Red Sindhi, Sahiwal, evolved in the subcontinent through long periods of natural and deliberate selection practiced by farmers could be further developed in the same way the European breeds were developed, and at a later stage crossing with European breeds could be considered for further grading rather than directly crossing these with European breeds from the beginning to upgrade them. Unfortunately, this ideal path was not followed for livestock breed improvement in India or later in East Pakistan and in Bangladesh rather the strategy the British left behind i.e., crossbreeding using exotic blood as the main or only strategy for breed improvement, has been continued.

Though exotic blood was introduced in the country by the British long time ago, by about 1990 , only about $5 \%$ of the cattle population was crossbred having exotic blood of some proportion with wide variation across districts (Alam, 1995). The rate was about $11.7 \%$ in 62 villages covered by intensive artificial insemination program; in urban areas, the ratio was about $20 \%$ and in sub-urban and rural areas about $10 \%$. Only $27.6 \%$ of cattle owners in these villages had crossbred cattle. More recent figures for crossbred cattle population are not available but it is assumed that about 3 million or $13 \%$ of 22.9 million cattle population in the country in 2007-08 were crossbred. So the genetic composition of the cattle population changed very slowly. Moreover, it has been chaotic due to the absence of a scientifically based long-term breeding policy for dairy development in the country, and the dairy processing companies have added to that chaos through their own AI services offered to farmers.

In Bangladesh, till today, a science-based systematically organized pragmatic breeding policy has never been formulated and adopted. Various breed improvement efforts have been made through different projects and programs using crossing zebu with exotic blood as the strategy with no sustained success. Selective breeding (selection and grading but maintaining 
Bang. J. Anim. Sci. 2010, 39(1\&2)

purity) of improved indigenous cattle never found any place in a consistent manner in breeding research and cattle breeding program to this day. The BAU, Mymensingh established a research dairy farm in 1958 and acquired stocks of several exotic breeds for experimental purposes. However, the university's breeding research has a rather poor history as there was no long-term goal of the breeding research program, and nearly all breeding stocks have been lost one way or another and no pedigree records on animals used in breeding research have been preserved in a manner to build accumulated evidence on breed performance.

The Central Cattle Breeding and Dairy Farm (CCBDF) established in 1960 at Savar under the Department of Livestock Services (DLS) has been pursuing a breeding program involving several imported breeds - both exotic and improved Indian and Pakistani breedsand maintaining a large number of breeding lines. In the absence of a national policy on breeding strategy for breed choices, experimentation at the station had no long- term goal and associated strategy to maintain record and accumulate knowledge for breed development in the country. Breeding experiments were designed following short-term project objectives so the goals changed very frequently as new projects were implemented with mostly donor funds. Consequently, many breed lines were sometimes maintained without any clear idea on breed attributes or criteria, other than milk yield, for comparison of breed lines and help make final choices. In 1983-84, out of 26 breeding animals kept at the CCBS, there were 2 Jersey, 5 Friesian, one Red Sindhi, one Sahiwal and the remaining 17 were of various combinations of the above breeds. At the district AI centre, out of 87 animals, there were two Red Sindhi, two Sahiwal, one Friesian and 82 of various combinations of the above (Jabbar and Ali, 1988). Also there was no long-term strategy on how these lines would be multiplied and disseminated if found suitable on the basis of the chosen criteria or attributes. Breeding services have been provided - initially through bull stations and natural service and later through AI services - without keeping proper long-term records of blood levels of parent materials or the progenies. The breeding strategy was more appropriate for commercial cattle/dairy farming somewhat practiced at the station, which was not likely to succeed in a situation where small-scale producers maintained few local cattle on poor quality feeds, mainly crop residues (Jabbar and Green, 1983; Jabbar and Ali, 1988).

A breeding policy document suggested by the DLS and provisionally approved by the government in 1982 included the following main points (quoted in Alam, 1995):

- For operation of the breeding policy, the country would be divided into urban, suburban and rural areas.

- In urban and sub-urban areas, crosses of pure Friesian bull and pure Sahiwal cow would be used to upgrade cattle. In rural areas, bulls with 50\% Friesian blood and $50 \%$ local blood would be used. This area-wise mating system would ultimately result in $50 \%$ or more Bos Taurus blood in upgraded animals.

- The CCBDF at would be the nucleus for maintaining breeding stocks and production of breeding bulls. Rajshahi Dairy Farm would maintain Friesian, Sahiwal and 
upgraded local animals, and Sylhet Dairy Farm would maintain Sahiwal and Red Chittagong Cattle.

- If required, breeding materials (semen/cattle) might be imported.

The basis of the choice of breeds as above and their promotion in some geographic areas were not explicitly stated or explained. However, these policy choices were not consistently implemented so expected results did not materialize. Rather the expansion of AI services by the DLS and other organizations made the situation worse in the absence of progeny records and other necessary steps required for cumulative improvement of the national herd. Currently the CCBS has 145 breeding bulls of various breeds and breed combinations. In 2008-09, 1.7 million dozes of semen were produced from these animals (Table 1). It is unclear what breeding lines can be developed in a sustained manner through dissemination of semen of these diverse breeds.

Table 1. Breeds of cattle kept at the Central Cattle Breeding Station, Savar, 2008-09

\begin{tabular}{|l|c|c|}
\hline \multicolumn{1}{|c|}{ Breed } & Number of bulls & Semen production (000 dozes) \\
\hline Sahiwal & 10 & - \\
Friesian & 2 & 39.6 \\
Local (nondescript) & 8 & 116.1 \\
Red Chittagong Cattle & 2 & 5.0 \\
Sahiwal x Friesian & 30 & 1556.9 \\
Local $\times$ Friesian & 93 & \\
Local $\times$ Friesian $x$ Friesian & - & \\
Sahiwal $\times$ Friesian $\times$ Friesian & - & 1717.6 \\
\hline Total & 145 & \\
\hline
\end{tabular}

- not available or applicable; Source: DLS, unpublished data

From a review of some experimental studies, comparative performance of some of the breeds can be observed. For example, Nahar et al. (1989) analyzed the productive and reproductive performances of crossbred cows of different breeds at Bangladesh Agricultural University (BAU) dairy farm. They observed the birth weight of $\mathrm{SL} \times \mathrm{LO}, \mathrm{SN} \times \mathrm{LO}, \mathrm{JR} \times \mathrm{LO}$ and $\mathrm{FN} \times$ LO to be $17.6 \pm 0.3,16.1 \pm 0.2,17.7 \pm 0.2$ and $21.4 \pm 0.2 \mathrm{~kg}$, respectively. Bhuiyan and Sultana (1994) collected data from CCBDF, Savar, Dhaka and studied the reproductive performances of exotic breeds and their crosses with LO cow. They found a highly significant $(\mathrm{P}<0.001)$ effect of genetic group, year of birth and sex on average birth weight of calves. They reported that the highest birth weight was in $1 / 8 \mathrm{LO} \times 7 / 8 \mathrm{FN}(26.77 \pm 1.08$ $\mathrm{kg}), 3 / 8 \mathrm{LO} \times 5 / 8 \mathrm{FN}(36.37 \pm 0.68 \mathrm{~kg}), \mathrm{F}_{2}$ crossbred of $\mathrm{LO} \times \mathrm{FN}(23.30 \pm 0.92 \mathrm{~kg})$ and the lowest birth weight for $\mathrm{F}_{1}$ crossbreds was in $\mathrm{LO} \times \mathrm{FN}(17.22 \pm 0.31 \mathrm{~kg})$. Nahar et al. (1989) studied the lactation length of 212 cows of different genotype using data maintained at the 
Bang. J. Anim. Sci. 2010, 39(1\&2)

BAU dairy farm, Mymensingh and a highly significant $(\mathrm{P}<0.01)$ effect of genetic group on lactation length was observed. They reported that lactation lengths of $\mathrm{LO} \times \mathrm{SN}, \mathrm{LO} \times \mathrm{SL}$, $\mathrm{LO} \times \mathrm{JR}$ and $\mathrm{LO} \times \mathrm{FN}$ were $269.29 \pm 2.67,295.54 \pm 3.33,341.48 \pm 3.12$ and $361.95 \pm 2.89$ days, respectively. Bhuiyan and Sultana (1994) investigated lactation length of 312 cows of various genotypes in CCBDF, Savar, Dhaka. They found that lactation length of LO $\times \mathrm{JR}$, $\mathrm{SL} \times \mathrm{FN}$ and $\mathrm{SL} \times \mathrm{LO}$ to be $241.18 \pm 10.49,286.67 \pm 7.94,251.45 \pm 4.51$ and $266.93 \pm 8.10$ days, respectively. Nahar et al. (1989) analyzed the lactation performance of different crossbred cows using data collected from BAU dairy farm and observed that highest lactation of $1992.39 \pm 19.57$ litters in $\mathrm{FN} \times \mathrm{LO}$ and the lowest of $997.97 \pm 19.10$ litters in SN $\times$ LO. On the other hand, Ahmed and Islam (1987) reported the production performance of different genotypes of CCBDF, Savar, Dhaka. Average lactation yield of LO, SN, SL, FN, JR, FN $\times$ JR cows was 962.37, 1123.20, 1324.57, 2423.16, 2264.24 and 1859.76 litters, respectively. Nahar et al. (1989) reported that the lowest age at first service in JR cows and highest in SL and SN grades. Rahman et al. (1987) reported that the age at first service of $\mathrm{LO}, \mathrm{SN}, \mathrm{SL}, \mathrm{LO} \times \mathrm{SN}, \mathrm{LO} \times \mathrm{JR}, \mathrm{LO} \times \mathrm{FN}, \mathrm{SN} \times \mathrm{SL}$ and $\mathrm{FN} \times \mathrm{SL}$ were 42.77, 51.05, 49.20, 43.20, 37.55, 31.89, 46.68, 46.29 and 47.95 months, respectively.

These results can be compared with actual farm level performance of these breeds based on a survey of 320 dairy farms conducted in 2000 in Pabna, Sirajganj and Manikganj as summarized in Table 2 (Jabbar et al., 2005). It appears that at the farm level, there are few differences in performance between the different crossbreeds, all of which performed better than local breed and that locals raised with crosses perform slightly better than when they are raised alone, indicating potential for improvement of local breeds under better management. However, more disaggregated data presented in the study report showed that average performance of all the breeds improved to some extent with farm size due to better feed supply and better management.

Table 2. Productive performance of different breeds at farm level in Pabna, Sirajganj and Manikganj districts, 2000

\begin{tabular}{|l|c|c|c|c|c|}
\hline \multicolumn{1}{|c|}{ Breed } & $\begin{array}{c}\text { Age at first } \\
\text { calving } \\
\text { (months) }\end{array}$ & $\begin{array}{c}\text { Calving } \\
\text { interval } \\
\text { (months) }\end{array}$ & $\begin{array}{c}\text { Lactation } \\
\text { length } \\
\text { (days) }\end{array}$ & $\begin{array}{c}\text { Highest average } \\
\text { daily milk yield } \\
\text { (liter) }\end{array}$ & $\begin{array}{c}\text { Average daily } \\
\text { milk yield (liter) }\end{array}$ \\
\hline Friesian cross & 31.5 & 11.7 & 248 & 11.8 & 8.5 \\
Jersey cross & 32.6 & 11.1 & 253 & 11.4 & 8.6 \\
Sahiwal cross & 35.0 & 12.0 & 250 & 10.5 & 7.8 \\
Red Sindhi cross & 33.9 & 12.8 & 207 & 8.4 & 5.8 \\
Local raised with & 34.5 & 12.4 & 245 & 6.5 & 4.9 \\
crosses & & & & & 4.1 \\
Only local & 39.5 & 12.6 & 247 & 5.6 & \\
\hline
\end{tabular}

Source: Jabbar et al. (2005) 
The new 'National Livestock Development Policy' formulated in 2007 and adopted by the then Care Taker Government in 2008 discussed several problems and issues regarding breed development, as mentioned earlier, and finally made recommendations for a plan of action targeted to three types of farms (high, medium and low level of input and management) over three time periods (up to 5 years, 6-10 years and 11 yrs and beyond). Also specific breeding related activities including choice of breeds and mating schemes for each farm type in each time period have been recommended. However, the scientific basis of these choices is not clearly stated in the document. For example, Holstein-Friesian has been recommended for high and medium input systems while a decision on the choice of Jersey has been put on hold until further experimentation. Similarly, Red Chittagong cattle has been recommended for promotion in low input systems though a long-term project that evaluated the average performance of this breed in situ in village conditions based on survey on farmers' opinion and ex situ at the experimental farm at BAU, Mymensingh found that in spite of superior management at the university farm, daily milk yield and lactation yield both were significantly higher in village conditions; lactation length and post partum heat period were significantly lower in village conditions and no significant differences were observed in terms of other productivity parameters (Table 3 ).

Table 3. Average performance of female Red Chittagong cattle under village conditions (in situ) and at the university farm (ex situ), 2004-2008

\begin{tabular}{|l|c|c|}
\hline \multicolumn{1}{|c|}{ Parameter } & In situ & Ex situ \\
& (mean \pm se) & (mean \pm se) \\
\hline Birth weight (kg) & $14.11 \pm 1.06$ & $13.89 \pm 0.34$ \\
Mature weight (kg) & $184.00 \pm 13.44$ & $185.87 \pm 21.35$ \\
Age at puberty (month) & $32.39 \pm 3.92$ & $28.68 \pm 1.42$ \\
Service per conception (no.) & $1.54 \pm 0.08$ & $1.57 \pm 0.12$ \\
Age at first calving (month) & $43.50 \pm 0.50$ & $39.89 \pm 1.88$ \\
Calving interval (month) & $14.84 \pm 0.30$ & $14.03 \pm 0.32$ \\
Post partum heat period (day) & $43.13 \pm 5.4$ & $122.75 \pm 6.36^{* *}$ \\
Lactation length (day) & $208.08 \pm 3.11$ & $242.17 \pm 8.33^{* *}$ \\
Lactation yield (kg) & $805.08 \pm 2.07$ & $516.94 \pm 35.89^{* *}$ \\
Daily milk yield (kg) & $2.70 \pm 0.09$ & $1.97 \pm 0.06^{* *}$ \\
\hline
\end{tabular}

** = Difference significant at less than 5\% level; Source: Bhuiyan (2008a)

There has been no voluntary farmer adaptation of this breed outside Chittagong, and the project further reported that "the performance and adaptability of Red Chittagong Cattle under the smallholder subsistence farming conditions of Bangladesh other than Chittagong district is unknown" and concluded that the scope of its promotion outside Chittagong was limited as "animal identification, registration and milk recording system for implementing breed improvement program successfully in the field are yet to operate in Bangladesh. System for the production of progeny tested Red Chittagong bull remains to be done" 
Bang. J. Anim. Sci. 2010, 39(1\&2)

Bhuiyan, 2008b). ${ }^{2}$ Yet, the new livestock policy document has made a clear choice in favor of promotion of Friesian and Red Chittagong for productivity improvement and seriously underemphasized or ignored the need for improvement of best performing local breeds or breed types/varieties such as Pabna, Munshigonj, Madaripur, North Bengal Grey etc as well as other sub-continental breeds (Ali, 2009). ${ }^{3}$ Overall, it is unclear how under the dominant system of smallholder farming, specific farm types will be identified or promoted and how cumulative breed improvement will be ensured by discriminatory supply of breeding materials.

\section{Materials and Methods}

Given the above background about breeding policy and strategy, a survey was conducted among teaching, research and development experts in the livestock sector as well as among farmers to solicit their perception on several aspects on choice of breeds and breeding strategies as discussed below.

Two broad stakeholder groups were considered for the survey: experts in the field of livestock education, research, development and extension, private sector industry; and livestock farmers, especially dairy farmers, having knowledge and experience about different breeds. The purpose of the survey was to collect information on the stakeholders' perceptions and opinions about long and short-term strategy with respect to breeds and breed development and about criteria for choice of breeds and suitability of different breeds for development/adaptation in the country. While expert opinions are sometimes sought in public decision making, such input usually comes through expert committees formed for specific purposes. However, there is hardly any evidence that in the past extensive consultation have been done with farmers to get their perspectives and experiences with improved and crossbreds in choosing breeding material for dissemination through programs such as bull stations or in more recent years through AI services.

A survey was conducted in 2008 among 128 livestock experts including 49 officials of the DLS (from Headquarters as well as AI Station in Savar, Diagnostic and Vaccine Production Centres in Mohakhali and Divisional and District Veterinary offices), 34 senior teaching staff of Veterinary and Animal Husbandry Faculties of Bangladesh Agricultural University,

\footnotetext{
${ }^{2}$ The BAU on-station work has been extended to on-farm conditions in a char village of Mymensingh district since January, 2009. The rationale for choice of this site is highly questionable given that the natural habitat of Red Chittagong is primarily a hilly terrain with different soil and vegetation characteristics than char land. However, it has been suggested that this rare and highly adaptable breed in the greater Chittagong district having high genetic variability within the population should be conserved for potential future development (Bhuiyan, 2008a, p. 39). Whether this breed is genetically related to red cattle varieties in the entire Southeast Asia region including the hilly states of Eastern India and southwest China should be investigated to exploit the benefits of any prevailing genetic diversity.

${ }^{3}$ The under-emphasis on local breeds or breed types is clear from the fact that possibility of its improvement has been given third priority after suggestion to use Friesian and Jersey for crossbreeding (MOFL, 2007, pp. 16-18).
} 
Mymensingh, 21 teaching staff of Chittagong Veterinary and Animal Science University, Sylhet Agricultural University and Dinajpur Veterinary College, 7 senior researchers from Bangladesh Livestock Research Institute, Savar, and 17 staff representing Participatory Livestock Development Program of PKSF, Milk Vita and some private enterprises. All the teaching and research staff and most of the other staff had at least a master's degree, only a few field level staff of the DLS had at least a bachelor degree. Out of 128 experts, 69 (53\%) had animal husbandry background, 51 (40\%) had veterinary background and 8 (7\%) had background in social sciences. The sample experts had on average 19.7 years of service experience.

Another survey was conducted among a purposive sample 200 dairy farmers from 11 districts - Pabna, Rangpur, Dinajpur, Thakurgaon, Jessore, Khulna, Barisal, Mymensingh, Jamalpur, Sylhet and Chittagong. These are the districts where the DLS staffs at district level were also interviewed. The purpose was to solicit farmers' opinion on criteria to be used in breed selection and their relative weight in breed evaluation and selection, and based on these criteria, assess the degree of suitability or performance of a number of breeds in Bangladesh conditions. All the sample farmers owned at least one dairy cow and some farmers owned additional dairy cows of one or more breeds and most farms also owned other types of animals such as draught cattle, heifers and young animals, small ruminants and poultry. Moreover, in selecting the farmers, some consideration was given on the degree of market orientation, i.e. involvement in milk sales, because such farmers were more likely to be interested in various breeds and their performance. The farmer sample is relatively small in relation to the entire country but the results are expected to reveal a number of important issues that highlight importance of incorporating expert and farmer perspectives in breed related policy choices and the need for wider consultation with farmers before major decisions are made.

For the two surveys, separate questionnaires were designed by the research team through extensive discussions. It was pre-tested before final implementation. Several members of the research team who are senior staff of the Department of Animal Breeding and Genetics of BAU, Mymensingh and some of their graduate students conducted the interviews. The collected data were computerized using SPSS software, which was also used for analysis employing mainly descriptive statistics.

\section{Results and Discussion}

\section{Perspectives on cattle breed development}

\section{Cattle breed development strategy options}

It is generally recognized that sustained development in the livestock sector must be based on stable and higher productive breeds. Countries that have developed breeds for their own environment have done so through long-term breeding policy and strategy. A period of 30-50 year vision/horizon is required for the development of any stable breed. No consistent and sustained policy and strategy was followed in our country in the past leading to haphazard 
Bang. J. Anim. Sci. 2010, 39(1\&2)

efforts and no cumulative sustained results. Given the above, the respondents were asked to rate a number of options for future action out of a total of 10 points i.e. allocate 10 points among the possible options so that relative importance of the options can be assessed. The answers are summarized in Table 4. It appears that no one wanted to continue with the current casual and haphazard approach. There is widespread support for adopting a long-term strategy for selection and grading of best performing local breeds and follows it up with crossbreeding with exotic blood at a later stage. There is also a small amount of support for adopting a strategy to directly adapt suitable exotic breeds.

Table 4. Average rating by experts on possible options for future action for breed improvement and development

\begin{tabular}{|lc|}
\hline \multicolumn{1}{|c|}{ Options for future action } & Points \\
\hline a) Allow the current casual and haphazard approach to continue for crossbreeding & 0 \\
using exotic blood & \\
b) Develop a long term policy and strategy for selection and grading of local breeds & 4 \\
and strictly implement it through proper budgetary, regulatory, administrative and & $(2.9)$ \\
policy support & \\
c) Follow b but allow crossbreeding with appropriate exotic blood for grading at the & 4 \\
appropriate stage of the process & $(2.9)$ \\
d) Use systematic adaptation of exotic blood as the strategy and identify suitable & 2 \\
exotic for adaptation (as pure or crossing with local) & $(2.3)$ \\
\hline Total points & 10 \\
\hline
\end{tabular}

Note: Figures in the parentheses are standard deviations

\section{Type of breed to be developed}

Local non-descript cattle are dual purpose breeds in the sense that males are used for draught and females for milk and reproduction. When cows are also used for draught, they may be described as draught cows or milk-and-draught cows, but they are not described as dual purpose in the usual sense. With mechanization and improved rural transport network, need for tillage and transportation has been declining and will decline further over time. If the long-term objective is to develop specialized dairy and beef breeds, male off-springs of dairy animals should have value as beef and/or draught for quite some time to come. Given this scenario, respondents were asked to allocate 10 points among three possible options- develop dairy breed, develop beef breed and develop dual purpose breed. The ratings are as follows: dairy breed: $5 \pm 3.0$, beef breed: $3 \pm 2.5$ and dual purpose breed: $2 \pm 3.3$. Thus there is strong preference for development of dairy breeds while the other two choices not only have lower preference, there is also wide variation in the opinions of experts on these two options as indicated by high standard deviations.

\section{Criteria or traits to be used for choice of exotic cattle breeds}

Whether exotic breeds are directly adapted or used to upgrade local breeds, suitable exotic breeds need to be identified and chosen. Such choice should be guided by certain traits or 
characteristics of the breeds based on research results and field level performance. Moreover, all traits may not be given equal weight in the selection process. So, prior to the questionnaire survey, a review of literature was done on studies and projects on breeding and breed development since the 1960s with a focus on criteria used for choice of breeds for experimentation for adaptation and for crossbreeding in cattle (Ali, 2009 and Bhuiyan, 2009). Most previous literature described what has been done on breeding, but rarely highlighted criteria used for breed choice, so the purpose of the new review was to summarize in a brief and succinct manner which traits, criteria or indicators have been used in past research and development projects for breed selection and performance. Information from this was expected to be useful to see what was done in the past and why. If available data did not answer these questions, that in it would be useful as without objective criteria, it would not be advisable to make breed choice and breeding service provision. In such a situation, expert and stakeholder opinions might provide guidance for immediate future plan of action. Unfortunately the review produced very little information on the traits used for breed choice.

In order to overcome this knowledge gap, the research team discussed in detail about possible traits that might be considered in any breed selection process, and came up with a list of nine traits. Then the respondents were asked if exotic breeds were to be chosen for local adaptation and/or for using for crossbreeding to upgrade local breeds, what should be the relative importance of these nine traits or criteria for choosing suitability of exotic breeds? Respondents were asked to allocate 100 points among the nine traits with the provision that a particular trait could be allocated zero if the respondent felt that no weight should be given to that trait in the selection process. This question was also put to the sample farmers, so responses of experts and farmers are shown in Table 5.

It appears that both experts and farmers have considered milk yield as the most important criterion for choice of breed for cattle improvement in the country but they have also given varying degrees of weight on a number of other criteria to be considered for breed selection such as reproductive performance, body size, disease risk, feed requirement and feed conversion efficiency. Moreover, farmers gave more weight to milk yield as a criteria than experts, and among the experts, animal husbandry experts gave more weight to milk yield than Veterinarians and social scientists. Veterinarians also gave slightly more weight on disease risk and reproductive performance compared to animal husbandry experts. There were no significant differences between farmers and experts in terms of weight given to beef yield and quality and feed requirement, but farmers gave lower weight than experts on the other criteria.

\section{Suitability of selected cattle breeds for adaptation}

Once the traits to be considered for breed choice were established, experts and farmers were 
Bang. J. Anim. Sci. 2010, 39(1\&2)

asked separately to apply each of those criteria to assess suitability or performance of Friesian, Jersey, Red Sindhi, Sahiwal, Pabna improved, Red Chittagong and local breeds for improvement of cattle. Matrix rating approach was used in soliciting the information. ${ }^{4}$ They were asked to rate a breed in terms of a trait out of 10 where 10 indicated most suitable and 0 not suitable at all. For example, if a respondent considered Friesian as moderately suitable for selection based on milk yield, the rating could be somewhere in the middle between 0 and 10. Overall suitability rating of a breed taking into account all the nine traits was also sought. The results for expert and farmer ratings are presented in Table 6 .

Table 5. Average weight (\%) given by experts and farmers on different traits or criteria for choosing suitable exotic cattle breeds for local adaptation and/or for crossbreeding to upgrade local breeds

\begin{tabular}{|l|ccc|c|c|c|}
\hline \multirow{2}{*}{ Traits } & \multicolumn{3}{c|}{ Experts by educational background } & \multirow{2}{*}{ Farmers } \\
\cline { 2 - 6 } & Veterinary & $\begin{array}{c}\text { Animal } \\
\text { Husbandry }\end{array}$ & Others & All & \\
\hline Body size & 10 & 11 & 8 & 10 & 14 \\
Milk yield & 30 & 36 & 31 & 33 & 46 \\
Draught quality & 3 & 3 & 0 & 3 & 6 \\
Beef yield and quality & 11 & 9 & 11 & 10 & 11 \\
Disease risk and vulnerability & 10 & 8 & 11 & 9 & 5 \\
Reproductive performance & 14 & 11 & 10 & 12 & 5 \\
Feed requirement/feed conversion efficiency & 9 & 9 & 9 & 9 & 8 \\
Climatic adaptability & 10 & 12 & 17 & 11 & 4 \\
Temperament (docile, aggressive) & 3 & 3 & 3 & 3 & 1 \\
\hline Total & 100 & 100 & 100 & 100 & 100 \\
\hline
\end{tabular}

Note: Column totals may not add up to 100 due to rounding error. Out of 200 farmer samples, 196 provided full information which was used in the analysis throughout the report. Difference between disciplinary background turned out to be not significant in answers to the remaining questions and issues, so further results are not presented by discipline.

It appears that relative preference or suitability of a breed varied to some extent between experts and farmers on several criteria and there was also difference in preference in terms of different criteria. When all the criteria were considered for overall choice of a breed, experts considered all the breeds except local almost equally suitable and local was also not too far

\footnotetext{
${ }^{4}$ The matrix rating method was originally developed by cognitive psychologists and has been applied to market research, urban geography, and agricultural technologies such as crop and tree varieties (Ashby et al., 1989; Negassa et al., 1991). Variants of the matrix rating method have been used in pastoral systems for investigating people's understanding and perceptions of the importance of different animal diseases and feed sources (WatersBayer and Bayer, 1994) and for assessing cattle breed preferences (Jabbar et al., 1998). A recent paper has discussed the relative merits of different approaches for assessing farmers' breeding objectives (see Duguma et al., 2010).
} 
behind for improvement of cattle in the country. Farmers rated all the breeds generally low compared to experts as average rating was about half that given by experts, but they also rated all the breeds almost equally. ${ }^{5}$ The reason for the difference between the levels of expert and farmer ratings needs some clarification.

Table 6. Average expert and farmer ratings of selected cattle breeds on the basis of different traits for their suitability in Bangladesh for using as pure breed or for crossbreeding to upgrade local breeds (each cell out of 10)

\begin{tabular}{|l|c|c|c|c|c|c|c|}
\hline \multicolumn{1}{|c|}{ Trait } & Jersey & Friesian & $\begin{array}{c}\text { Red } \\
\text { Sindhi }\end{array}$ & Sahiwal & Pabna & $\begin{array}{c}\text { Red } \\
\text { Chittagong }\end{array}$ & Local \\
\hline Expert ratings & & & & & & & \\
Body size & 5.8 & 6.2 & 6.5 & 5.7 & 6.2 & 5.8 & 5.1 \\
Milk yield & 6.9 & 8.2 & 5.1 & 5.4 & 5.0 & 4.0 & 3.1 \\
Draught quality & 2.3 & 2.5 & 4.4 & 5.1 & 5.3 & 5.0 & 5.4 \\
Beef yield and quality & 4.9 & 5.2 & 4.5 & 4.4 & 4.9 & 4.2 & 4.5 \\
Disease risk and & 5.5 & 5.1 & 5.2 & 6.1 & 5.0 & 4.7 & 4.1 \\
vulnerability & & & & & & & \\
Reproductive performance & 5.7 & 6.1 & 5.4 & 5.4 & 5.3 & 5.1 & 4.8 \\
Feed requirement/feed & 5.5 & 5.3 & 5.2 & 5.3 & 5.0 & 5.0 & 4.6 \\
conversion efficiency & & & & & & & \\
Climatic adaptability & 4.6 & 4.8 & 4.0 & 6.5 & 6.9 & 6.9 & 7.2 \\
Temperament & 6.1 & 5.9 & 5.5 & 5.8 & 6.3 & 5.7 & 5.1 \\
Overall & 7.1 & 6.9 & 6.7 & 7.0 & 7.4 & 7.0 & 6.2 \\
\hline Farmer ratings & & & & & & & \\
Body size & 2.8 & 4.0 & 3.0 & 3.6 & 2.6 & 2.2 & 2.1 \\
Milk yield & 2.9 & 5.2 & 3.0 & 3.9 & 1.9 & 1.8 & 2.1 \\
Draught quality & 1.8 & 2.1 & 2.5 & 2.9 & 3.5 & 2.7 & 3.0 \\
Beef yield and quality & 2.4 & 3.3 & 3.2 & 3.8 & 2.9 & 2.8 & 2.9 \\
Disease risk and & 2.0 & 2.6 & 2.6 & 3.1 & 2.6 & 2.9 & 2.8 \\
vulnerability & & & & & & & \\
Reproductive performance & 2.6 & 3.3 & 2.8 & 3.3 & 2.4 & 2.7 & 2.6 \\
Feed requirement/ & 2.7 & 3.1 & 2.8 & 3.3 & 2.5 & 2.8 & 2.7 \\
feed conversion efficiency & & & & & & & \\
Climatic adaptability & 2.2 & 2.8 & 2.9 & 3.4 & 2.9 & 3.3 & 3.0 \\
Temperament & 2.5 & 3.2 & 2.7 & 3.2 & 2.4 & 2.5 & 2.4 \\
\hline Overall & 3.3 & 2.8 & 3.4 & 2.6 & 2.6 & 2.6 \\
\hline
\end{tabular}

${ }^{5}$ The farmer ratings appear to be consistent with farmer reported performance of these breeds based on several criteria as shown in Table 2. 
Bang. J. Anim. Sci. 2010, 39(1\&2)

Experts' rating of suitability of these breeds are higher perhaps because they have used theoretical knowledge and some knowledge based on research and on-station performance records (even though evidence of such information could not be traced in the literature as mentioned earlier ${ }^{6}$ ) or observations on field level performance. On the other hand, not every sample farmer owned or managed all the breeds they rated rather their ratings were based on practical experience and/or observation in diverse and rough real world situations. Of the total number of dairy cows owned by these farms at the time of the survey, $40 \%$ were local, $36 \%$ Friesian crosses, $11 \%$ Sahiwal crosses, 5\% Red Sindhi crosses, 5\% Red Chittagong or Red Chittagong crosses, 2\% Jersey crosses and 1\% Pabna improved. Farmers were asked about the level of their awareness or knowledge about traits and good husbandry methods required for these breeds except local as it was assumed they were traditionally knowledgeable about it. It appeared that $63 \%$ of the farmer respondents had no proper knowledge about good traits and husbandry practices of various breeds, $10 \%$ had very little or poor knowledge, $19 \%$ had good/medium level and $8 \%$ had very good knowledge. These ratios also differed between the breeds, and knowledge about Friesian crosses appeared to be better than about the other breeds (Table 7).

Table 7. Percentage of farmer respondents according level of knowledge about traits and good husbandry practices for different exotic/crossbreds of cattle

\begin{tabular}{|c|c|c|c|c|c|}
\hline \multirow[t]{2}{*}{ Breeds } & \multirow{2}{*}{$\begin{array}{l}\text { \% cows of } \\
\text { the sample } \\
\text { farms }\end{array}$} & \multicolumn{4}{|c|}{$\begin{array}{l}\text { \% respondents having knowledge about good managemen } \\
\text { practices for the breed }\end{array}$} \\
\hline & & Very good & Good/medium & Little/poor & Not at all \\
\hline Friesian cross & 36 & 3 & 51 & 16 & 30 \\
\hline Jersey cross & 2 & 1 & 7 & 12 & 80 \\
\hline Red Sindhi cross & 5 & 9 & 23 & 5 & 63 \\
\hline Sahiwal cross & 11 & 7 & 28 & 11 & 54 \\
\hline Pabna improved & 1 & 13 & 8 & 5 & 74 \\
\hline Red Chittagong & 5 & 16 & 14 & 7 & 63 \\
\hline Local & 40 & na & na & na & na \\
\hline All & 100 & 8 & 19 & 10 & 63 \\
\hline
\end{tabular}

Note : Knowledge level for local was not collected. Average for all breeds is based on all except local

This poor knowledge base about crossbreds might have resulted in poor performance of crossbred cows that these farms owned and managed or observed around them. This is evidenced by the highest average daily milk yield of the various breeds owned by the sample farms (Table 8). For each breed, yield levels were apparently somewhat higher in certain districts as the ranges of average between districts indicate. These yield levels were likely to

\footnotetext{
${ }^{6}$ For example, one author stated that best performing local breeds are preferred by producers because of better disease resistance, ability to thrive on roughages and less requirement for high cost technologies (Rahman, 2003). However, whether such traits were objectively assessed and were actually used for breed selection in various breed development efforts by the DLS and other private sector AI service providers remain unclear.
} 
be much lower than the expectation of the sample farmers or lower than their potential even under adverse Bangladesh conditions. So, the perceptions or ratings on different traits of these breeds most likely have been influenced by poor knowledge about the breeds as well as their poor performance on their farms.

Table 8. Highest daily average milk yield (kg) of different breeds owned by the sample farmers

\begin{tabular}{|l|c|c|}
\hline \multicolumn{1}{|c|}{ Breed } & $\begin{array}{c}\text { Highest daily average milk yield per } \\
\text { cow (kg) }\end{array}$ & $\begin{array}{c}\text { Range among district averages } \\
\text { (kg) }\end{array}$ \\
\hline Friesian cross & 7.4 & $3.0-11.5$ \\
Jersey cross & 6.3 & $4.0-8.5$ \\
Red Sindhi cross & 4.4 & $3.0-7.0$ \\
Sahiwal cross & 5.0 & $2.5-8.3$ \\
Pabna improved & 2.0 & na \\
Red Chittagomng & 3.6 & na \\
Local & 2.4 & $1.3-3.8$ \\
\hline
\end{tabular}

Note: Red Chittagong was available only in Chittagong, so inter-district range was not relevant

Two lessons emerge from these ratings. First, lower ratings by farmers imply that the breeds are performing at much below their expected potential which might be partly due to farmers' lack of knowledge on good husbandry and partly due to poor adaptation of the breeds to the local conditions. So, the level of performance of these breeds need to be improved significantly to approach their true potential both through imparting knowledge and better adaptive research if wide adoption is to be expected. Second, although rating levels were different between experts and farmers, at their own scale of rating they considered all the breeds almost equal which indicated that choice of breeds for cattle improvement could be made out of a larger array of breeds rather than just Friesian and Red Chittagong as has been adopted as a strategy in the Livestock Policy document.

\section{Farmers' breeding practices and their implications}

Sustained improvement of breed will depend on what breeds and breeding materials will be promoted and disseminated and how farmers will practice breeding in their herds. The new breeding policy adopted a strategy for promotion of Friesian and Red Chittagong with negligible emphasis given on local breeds. For exotic blood, AI is going to be the only or main means of breeding but in case of other breeds including some crossbreds both natural service and AI are expected to be options. In this light, farmer respondents were asked about their current use of AI for breeding and reasons for not using AI at all or irregularly.

It appears that $59 \%$ of the sample farmers regularly used AI while $22 \%$ used irregularly and $19 \%$ did not use at all. So the use rate in the sample seems quite high in relation to the national average (about 15\% of national cattle population are crossbred) and the reason is 
Bang. J. Anim. Sci. 2010, 39(1\&2)

perhaps that these farmers have been purposively selected due to their ownership of crossbred cattle and more market orientation. Non-users or irregular users of AI gave several reasons for doing so. In descending order of importance they are unavailability/ inaccessibility (44\%), low conception rate (33\%), have access to bull service nearby (12\%), AI centre far from home (11\%), doctors/AI assistants not available or do not come (8\%), small size of cow, not suitable for large size animal (8\%), high disease risk (5\%) and no knowledge about AI (3\%). Thus problems of access and perceptions about its suitability or risk are reasons for non-use or irregular use. Irrespective of their relative frequency, each reason mentioned deserve careful consideration because dissemination of breeding material through AI will be constrained by these problems, so appropriate steps have to be taken to resolve them.

Among the farmers who used AI regularly or irregularly, some had only local, some had only crossbred and others had both local and crossbred animals. When they had only one type of animal obviously they bred that type of animal by AI. But among farmers who had both local and crossbred animals, 19\% said they used AI only for breeding local breed, 50\% said they used AI only for crossbreed while 31\% said they used AI for both. The reasons for such choices or practices were not explored in the survey but such practices may create problems for sustained breed improvement through AI because it is unclear how the inter-generational make up of the herds of these farmers will look like.

Farmers who used AI regularly or irregularly were asked semen of which cattle breed did they use for insemination? The responses are summarized in Table 9. It appears that some AI users used semen of only one breed while others used two in different combinations. Fifty four percent used only Friesian and another 30\% used Friesian and one of four other breedsSahiwal, Red Sindhi, Pabna and Jersey. Either on its own or in combination with another breed, 28\% farmers used Sahiwal semen, 15\% used Red Sindhi semen, 3\% used Pabna semen and 2\% used Red Chittagong semen. Thus Friesian semen is the most widely disseminated and used in AI programmes but a significant proportion of farmers apparently had access to semen of a number of other breeds - some more widely than others. The question is, in the absence of proper progeny records, how the cumulative benefits of crossbreeding through such haphazard breeding practices will be captured and maintained for sustained breed improvement?

Farmers who used AI were asked if they asked for semen of any specific breed(s). Eighty percent of AI users said they asked for semen of specific breed(s) and 20\% said they asked for AI without asking for semen of any specific breed. Those who asked for semen of specific breed were asked if they got what they asked for. Fifty eight percent of those who sought semen of specific breed got it; remaining $42 \%$ were given what was available. Those who did not ask for semen of any specific breed were asked about reason for doing so. Fifty one percent said they had no knowledge about characteristics of any specific breed, 33\% said they had no knowledge on what was available, and $16 \%$ said their cows had reproductive/ disease problem but had no knowledge on what was suitable for them. Here again, there are 
supply and demand side problems in shaping the genetic composition of the herds through AI.

Table 9. Percentage of AI users according semen of cattle breed used for insemination

\begin{tabular}{|l|c|}
\hline \multicolumn{1}{|c|}{ Semen of breed } & AI using farmers used (\%) \\
\hline Friesian & 54 \\
Friesian and Sahiwal & 17 \\
Sahiwal & 10 \\
Friesian and Red Sindhi & 9 \\
Friesian and Pabna & 3 \\
Red Sindhi & 3 \\
Red Sindhi and Red Chittagong & 2 \\
Friesian and Jersey & 1 \\
Red Sindhi and Sahiwal & 1 \\
\hline Total & 100 \\
\hline
\end{tabular}

Given the perspectives of experts and farmers described above, it is conceivable that the implementation of the new Livestock Policy, especially its breeding strategy focused on Friesian and Red Chittagong with marginal emphasis given on improvement of best performing local breeds, will lead to a cattle population with varying proportion of exotic blood of different breeds but may lead nowhere in terms of long-term breed development in the country. Indiscriminate breeding with choices limited to two specific breeds without proper progeny records may also lead to eradication of locally adapted best performing genetic resources from the country. ${ }^{7}$

\section{Other issues in breed development}

\section{Options for goat and sheep breed development}

Black Bengal is the indigenous breed and its adaptation and suitability under Bangladesh conditions especially due to high disease resistance and high prolificacy is well established. In the past, Jamnapari, a breed more adapted to the sub-humid/semi-arid condition of Bihar and Northern India, was introduced in this part of the sub-continent initially through informal trade but later attempts were made to use this for crossbreeding to upgrade Black Bengal. The result has been rather unsatisfactory in terms of life time productivity so adoption of this breed in pure form or for crossbreeding has been minimal. However, a debate about its potential for goat breed improvement in the country remains. So experts were asked to

\footnotetext{
${ }^{7}$ Indian dairy developments has been aided to some extent by improved buffaloes and increased crossbred cattle in some key states in the north and west of the country while elsewhere in other states crossbred population is quite small. However, environmentalists expressed concern about negative consequences of indiscriminate crossbreeding on indigenous genetic resources and loss of diversity in the genetic composition of Indian livestock (Khurana, 1997).
} 
Bang. J. Anim. Sci. 2010, 39(1\&2)

consider three options - selection and grading of Black Bengal for further improvement, adaptation of Jamnapari, and start with selection and grading of Black Bengal but later use Jamnapari for crossbreeding for upgradation. They were asked to allocate 10 points among these options with the provision that an option could be rated zero if it was considered totally unsuitable. The results show that average rating was respectively 7,1 and 2 . Thus, there is overwhelming support for concentration of efforts on improvement of the Black Bengal though some preference for adaptation of Jamnapari or its use for crossbreeding still remains. Farmers were asked about two advantages and two disadvantages of Jamnapari breed. Responses came in various combinations. Taken all the responses together, in descending order of importance, advantages reported are large body size, higher milk yield, better meat quality, rapid growth, good looking and high market price. The reported disadvantages in descending order of importance are high disease risk, high mortality, requirement of high quality feed and stall feeding, and small litter size.

Sheep constitute less than $10 \%$ of the small ruminant population in the country (BBS, 2010). Generally sheep meat is not a preferred commodity among Bangladeshi consumers. Urban butchers sell sheep meat as goat meat to unsuspecting buyers (Islam and Jabbar, 2010). Local breeds do not produce good quality wool. In temperate climate, economics of sheep depends on meat as well as wool yield and quality. In dryland/arid areas, sheep and goats are raised based on ecological adaptability and wool may not be a major criteria for selection or economy. In the past, research has been conducted in the country to adapt temperate sheep breeds or use them for crossbreeding with local breeds with poor outcomes and little adoption, if any.

Given the above scenario, experts were asked about the relative importance to be given to goat and sheep research for breed development. They were asked to allocate 10 points between two options: development of better productive and stable goat breed(s) and development of better productive and stable sheep breed (s). On average they rated 7 and 3 for the two options respectively. This indicates that experts are clearly in favor of improving goat breeds, especially Black Bengal. Some have also put much more emphasis on sheep research for development compared to its share in the small ruminant population. Very few farmers rear sheep and have knowledge about sheep rearing, so this question was not put to them.

\section{Breed related research on poultry and ducks}

Poultry and ducks are principal sources of meat consumed in the country. Several attempts have been made to improve local scavenging chicken. Cockerel exchange program of the government has been one of the more long lasting effort but with poor outcome. Public sector institutions - DLS, BLRI and universities- have conducted highly insufficient research on poultry and duck breeding. Rapid expansion of the commercial poultry sector has been based on imported genetic material without much adaptive research. Only recently large commercial enterprises have initiated some activities in this line. Given the above situation, experts were asked to allocate 10 points among five options irrespective of whether the research should be done by public or private sector. Average rating for each option is shown 
in Table 10. It appears that the experts prefer a balanced portfolio of research on local and commercial breeds and the purpose includes adaptation, improvement and conservation.

Table 10. Expert ratings of options for research on poultry and ducks

\begin{tabular}{|l|c|}
\hline \multicolumn{1}{|c|}{ Option } & Average rating \\
\hline Selection and grading of local non-descript breeds/varieties & 2.1 \\
Conservation of local genetic resources & 2.9 \\
Adaptation of exotic breeds for commercial poultry/duck industry & 3.0 \\
Crossbreeding exotic with graded local breeds & 1.8 \\
Other & 0.3 \\
\hline Total & 10.0 \\
\hline
\end{tabular}

\section{Allocation of resources among species for breeding research}

No objective basis or criteria is followed in the country for allocation of research resources (human and financial) among various sectors of the economy. Moreover, research activities are spread between various ministries and institutions which get budget allocation independently so there is no central mechanism to judge if there is any synergy between a sector's contribution and potential contribution to the economy and its share of research resources. This anomaly is not unique for the livestock sector so it can't be fixed easily. However, irrespective of the level of resources available for breeding research, some rational allocation among various species should be exercised. From that point of view, experts were asked to allocate 10 points among breeding research activities on various species. Average ratings turned out to be as below: cattle 3.3, buffalo 1.0, goat 2.1, sheep 0.8 , poultry 2.0, ducks 0.8 . These ratings suggest that experts are suggesting significantly higher allocation to buffalo, sheep and duck research in relation to their present or potential contribution. Experts were not asked to give reasons for their suggested allocation but if these rates are to be applied in reality, strong justification based on objective criteria has to be found.

\section{Implications and Conclusions}

In Bangladesh, till today, a science based systematically organized pragmatic breeding policy has never been formulated and adopted. Various breed improvement efforts have been made through different projects and programs using crossing zebu with exotic breeds as the strategy with no sustained success. Breed improvement efforts have been made through ad hoc short-term projects without any long-term clear goals. In formulating and adopting such projects and policies neither rigorous scientific research results have been used nor the perspectives of stakeholders-experts and farmers- have been adequately taken into account. The latest provisional livestock policy document approved in 2008 adopted a strategy to promote principally Friesian crosses and Red Chittagong for breed improvement with marginal emphasis given on improvement of local breeds, breed types/varieties such as Pabna, Munshigonj, Madaripur, North Bengal Grey etc. as well as other sub-continental breeds. The basis of these choices is unclear. 
Bang. J. Anim. Sci. 2010, 39(1\&2)

In this paper, results of a survey of 128 teaching, research and development experts and 200 market oriented farmers with at least one dairy cow are presented to highlight their perspectives on breed development strategy options and criteria to be used in choosing breeds for adaptation or for using for crossbreeding to improve local cattle. Perspectives on a number of other breed related issues are also presented.

Experts suggested that development of dairy breed should be top priority but beef and dual purpose breeds should also be important objectives in breed development or improvement programs. Both experts and farmers considered milk yield as the most important criteria for choice of breeds but there are several other criteria like disease resistance, feed requirement and feed conversion efficiency, yield and quality of beef etc that need adequate attention in breeding research and development and in the choice of breeds for adaptation and improvement of local breeds.

Expert rating of different breeds known and tried in the country in terms of traits are fairly similar. Farmer ratings are much lower than expert ratings, implying farmer perception and experience of lower overall suitability of promoted breeds/crossbreds under farm conditions. But few farmers appear to have adequate knowledge about traits and husbandry methods of different crossbreds to obtain optimal performance. Moreover, about $40 \%$ of market oriented farmers do not use AI, main reasons are unavailability/inaccessibility and low conception rate. Many AI users do not ask for semen of specific breed because of lack of knowledge about availability and suitability. Expert and farmer ratings together indicate that choice of breeds for cattle improvement could be made out of a larger array of breeds rather than just Friesian and Red Chittagong as has been adopted as a strategy in the Livestock Policy document.

Given the perspectives of experts and farmers described above, it is conceivable that the implementation of the new Livestock Policy, especially its breeding strategy focused on Friesian and Red Chittagong with marginal emphasis given on improvement of best performing local breeds will lead to a cattle population with varying proportion of exotic blood of different breeds but may lead nowhere in terms of long term breed development in the country. Indiscriminate breeding with choices limited to two specific breeds without proper progeny records may also lead to eradication of locally adapted best performing genetic resources from the country.

The findings suggest current chaotic AI delivery should stop and a combination of different strategies for breed improvement should be adopted and breeding research, development and service delivery need to be designed taking cognizance of perspectives of experts and farmers.

Expert opinions on goat research strategy show overwhelming support for improvement of Black Bengal goat but research on other breeds is also advocated. In case of balance between goat vs sheep research, they emphasize goat research but some also give more weight to sheep than its contribution or potential contribution to the sector. Similarly opinions on 
allocation of resources for breeding research on different species overall show some subjective bias in favor of sheep, buffalo and ducks inconsistent with their contribution or potential contribution. In order to make most effective use of limited research resources, it will be necessary to develop objective criteria and supporting data to justify such pattern of resource allocation if indeed such allocation pattern is advocated or practiced.

The farmer sample in the study was relatively small in relation to the entire country but the results have revealed a number of important issues that highlight importance of incorporating farmer perspectives along with expert opinions in breed related policy choices and the need for wider consultation with farmers before major decisions are made.

\section{Literature Cited}

Ahmed, Z. and Islam, T. S. 1987. Cattle breeding program through artificial insemination in Bangladesh. Artificial Insemination Extension Project Report, Central Cattle Breeding Station, Dhak. pp. 68.

Alam, J. 1995. Livestock resources in Bangladesh - Present status and future potential. University Press Ltd. Dhaka, pp. 134.

Ali, S. Z. 2009. Breed and breeding services development in Bangladesh. Unpublished paper.

Ashby, J. A., Quiros, C. A. and Rivers, Y. M. 1989. Farmer participation in technology development: work with crop varieties. Farmer First: In: Chambers, R. Pacy, A., and Thrupp, L. A. (Eds) Farmer Innovation and Agricultural Research. Intermediate Technology Publications, London, pp. 115-131.

BBS. 2009. Agricultural sample survey of Bangladesh 2005- National volume. Bangladesh Bureau of Statistics, Dhaka.

Bhuiyan, A K. F. H. 2008a. Research on characterization, conservation and improvement of Red Chittagong cattle in Bangladesh. Final Technical Report to the United States Department of Agriculture. Department of Animal Breeding and Genetics, Bangladesh Agricultural University, Mymensingh, pp. 112.

Bhuiyan, A K. F. H. 2008b. Characterization, conservation and improvement of Red Chittagong cattle in Bangladesh - Lessons learnt and way forward. Key note paper presented at a National Workshop on Red Chittagong Cattle Project. Department of Animal Breeding and Genetics, Bangladesh Agricultural University, Mymensingh, 22 November, 2008.

Bhuiyan, A. K. F. H. 2009. Breeds and breeding development activity in Bangladesh. Unpublished data.

Bhuiyan, A. K. F. H. and Sultana, R. 1994. Analysis of performance of exotic cattle breeds and their crosses in Bangladesh. Proceedings of the $5^{\text {th }}$ World Congress on Genetics Applied to Livestock Production, 20: 355-358.

Conway, G. 1999. Feeding the world - Biotechnology and farmers as experimenters. Second Annual Peter Doherty Distinguished Lecture, 24 September 1999, International Livestock Research Institute, Addis Ababa, Ethiopia. 
Bang. J. Anim. Sci. 2010, 39(1\&2)

Duguma, G., Mirkena, T., Haile, A., Iñiguez, L., Okeyo, A. M., Tibbo, M., Rischkowsky, B., Sölkner, J. and Wurzinger, M. 2010. Participatory approaches to investigate breeding objectives of livestock keepers. Livestock Research for Rural Development 22 (4) Article \#64. Retrieved April 2, 2010, from http://www.lrrd.org/lrrd22/4/dugu22064.htm

Islam, S. M. F. and Jabbar, M. A. 2010. Consumer preferences and demand for livestock products in urban Bangladesh. Research Report 23, International Livestock Research Institute, Nairobi, Kenya, pp. 86.

Jabbar, M. A. 2004. Smallholder livestock for poverty alleviation: Issues and prospects with some examples from Asia. Keynote address presented at the Bangladesh Agricultural Research Council, Dhaka, 12 May, 2004. pp. 36.

Jabbar M. A. and Ali, S. Z. 1988. The limitations of cross breeding for improvement of cattle in Bangladesh, Oxford Agrarian Studies, 17: 29-56.

Jabbar, M. A. and Green, D. A. G. 1983. The status and potential of livestock within the content of agricultural development policy in Bangladesh. Department of Agricultural Economics, University of Wales, Aberystwyth, UK, pp. 103.

Jabbar, M. A., Islam, S. M. F., Delgado, C., Ehui, S., Akanda, M. A. I., Khan, M. I. and Kamruzzaman, M. 2005. Policy and scale factors influencing efficiency in dairy and poultry production in Bangladesh. International Livestock Research Institute, Nairobi, Kenya; Systemwide Livestock Programme, ILRI, Addis Ababa, Ethiopia, and Bangabandhu Shaikh Mujibur Rahman Agricultural University, Gazipur, Bangladesh, pp. 70.

Jabbar, M. A., Swallow, B. M., D’Iteren, G. D. M. and Busari, A. A. 1998. Farmer preferences and market values of cattle breeds of West and Central Africa. J. Sustainab., Ag., 12: 21-47.

Jabbar, M. A., Swallow, B. M., and Rege, E. 1999. Incorporation of farmer knowledge and preferences in designing breeding policy and conservation strategy for domestic animals. Outlook on Agriculture, 28(4): 239-24.

Khurana, I. 1997. Vanishing breeds. Down to Earth, 6: 27-33.

MOFL. 2007. National livestock development policy, Ministry of Fisheries and Livestock, Government of the People's Republic of Bangladesh, Dhaka, pp. 40.

Nahar, N., Mostafa, K. G. and Amin, M. R. 1989. A comparative study on the performance of F1 crossbred cows. Bang. J. Anim. Sci., 18: 55-62.

Negassa, A., Benti, T., Franzel, S., Gemechu, G. and Dadi, L. 1991. The introduction of an early maturing maize (Zea mays) variety to a mid-altitude farming system in Ethiopia. Experimental Agriculture, 27: 375-383.

Rahman, M. H. 2003. Veterinary services and animal production and health. Background paper for Livestock sector Review and Future Development Assessment. Prepared for The Policy and Planning Support Unit, Ministry of Fisheries and Livestock, Government of the People's Republic of Bangladesh, Dhaka, pp. 74.

Wallace, R. 1888. India in 1887. Oliver and Boyd. Edinburgh, UK, pp. 536.

Waters-Bayer, A. and Bayer, W. 1994. Planning with pastoralists: PRA and More-A review of methods focused on Africa. Deutsche Gesellschaft fur Technische Zusammenarbeit (GTZ) Division 422 Working Paper. Druckerei Kinzel, Gottingen, Germany. 